\title{
STORAGE OF RETINOIDS AND BETA-CAROTENE IN THE GENITAL ORGANS OF JAPANESE QUAIL
}

\author{
Annamária KERTI and L. BÁRDOS* \\ Department of Animal Physiology and Health, University of Agricultural Sciences, \\ H-2103 Gödöllö, Páter K. u. 1, Hungary
}

(Received April 30, 1998; accepted June 15, 1998)

\begin{abstract}
The present study was designed to investigate the effect of a one-month feeding of retinyl acetate (RA) on the retinol (ROL), retinyl palmitate (RP) and $\beta$ carotene $(\mathrm{BC})$ levels in the blood, testicles and ovarian follicles of adult Japanese quails. The basal diet (containing vitamin A at $10 \times 10^{3} \mathrm{IU} / \mathrm{kg}$ ) was supplemented with $100 \times, 500 \times$ and $1000 \times 10^{3} \mathrm{IU} / \mathrm{kg}$ RA in Groups I, II and III in both sexes. Plasma vitamin A levels rose in all groups. The elevations were caused basically by the RP fraction. The ROL concentration increased only slightly, indicating saturation of the blood binding/transport system. Plasma BC was depressed in both sexes. RA feeding resulted in high RP concentration in the genital organs (testicles and ovarian follicles), indicating subclinical hypervitaminosis, while the $\mathrm{BC}$ content of genital organs decreased considerably. The retinoid and $\mathrm{BC}$ concentration of ovarian follicles (F1-F5) was in the same range, indicating continuous retinoid and carotene transport during the fast maturation period. Retinoid content of the genital organs was higher in layers than in roosters. BC deposition was decreased both in the testicles and in the follicles, indicating a competition between RP and BC for the storage capacity of organs.
\end{abstract}

Key words: Vitamin A, retinol, retinyl palmitate, ß-carotene, blood, ovarian follicle, testicle, Japanese quail

Reports have suggested that high doses of vitamin A or $\beta$-carotene (BC) disrupt the oestrous cycle in mammals (Gellert, 1977). The specific role of retinoids (formerly vitamin A) and/or carotenoids (especially BC) in avian reproduction has not been clearly defined (Thompson et al., 1969; Bermudez et al., 1993). Egg production and hatchability of eggs laid by hens given no dietary vitamin A supplementation were found to be significantly lower. Egg and chick weight were not consistently altered by vitamin A status (Naber and Squires, 1993).

This study was designed to investigate the effects of a one-month feeding of retinyl acetate (RA) on the retinol (ROL), retinyl palmitate (RP) and $\beta$-carotene (BC) levels of the blood, testicles and ovarian follicles in adult Japanese quails.

*to whom correspondence should be addressed: lbardos@fau.gau.hu 


\section{Materials and methods}

\section{Experimental animals}

At six weeks of age, mature Japanese quail hens and roosters were divided into six groups (30 birds in each) and fed a supplemented diet for four weeks.

The basal diet containing vitamin $\mathrm{A}$ in a dose of $10,000 \mathrm{IU} / \mathrm{kg}$ was supplemented with $100 \times, 500 \times$ and $1000 \times 10^{3} \mathrm{IU} / \mathrm{kg}$ RA in Groups I, II and III in both sexes.

At the beginning and in weeks 2 and 4 of the experiment, five birds of each group were slaughtered by sudden decapitation. Blood was gathered into heparinized tubes and the plasma was separated by centrifugation. The genital organs of the animals were quickly removed. All samples were stored deep frozen until analysed. The experiments were carried out with the consent of the Animal Experiments Board of the University.

\section{Vitamin A preparation}

The required dietary level of vitamin A was adjusted by the use of Vitamin A capsules 50,000 IU (EGIS, Budapest) commonly available in pharmacies. The active ingredient of this preparation is RA (Hoffman-La Roche, Basle).

\section{Retinoid and $\beta$-carotene analysis}

Retinoid analysis was carried out using the method described by Biesalski et al. (1986), modified by us as follows. Retinoids and carotenoids were extracted from the blood plasma, follicles and testes with n-hexane containing an antioxidant $(50 \mathrm{mg} / \mathrm{L} \mathrm{BHT})$. The extract was injected onto a Si-100-S $10 \mathrm{CN}$ column (BST Ltd., Budapest). The elution parameters were: mobile phase nhexane : methanol (99.5:0.5), flow rate $1.51 \mathrm{ml} / \mathrm{min}$ at 50 bar. UV detection was carried out at $325 \mathrm{~nm}$. Concentrations of $\beta$-carotene were measured in a similar arrangement but detection was carried out at $450 \mathrm{~nm}$. The peaks were identified using standard compounds: retinol (ROL) (Sigma, St Louis), retinyl palmitate (RP) (NBC, Cleveland), and $\beta$-carotene (BC) (Merck, Darmstadt). Concentrations were determined from the peak heights obtained by measuring the standard dilutions.

\section{Results and discussion}

\section{Laying quails}

Plasma vitamin A levels were increased in all treated groups. With supplementation, blood ROL concentration increased slightly more powerfully in laying hens than in roosters, indicating saturation of the binding/transport system of the 
blood. Alterations in plasma vitamin A levels were caused basically by an elevation of the RP fractions. The retinyl ester (RP) concentration of hens was much higher (twice, 12 times and 13 times in Groups I, II and III, respectively) in the second week of the experiment as compared to the level measured at the beginning, but that was followed by only a mild increase. The change was pronounced in laying hens, especially in those of Group III. Plasma BC was depressed in all treated groups and showed an inverse correlation to RA supplementation during the experiment (Table 1). Our results are in line with those of Weiser et al. (1992), who found that after feeding vitamin A to chickens in a dose of 10,000 $30,000 \mathrm{IU} / \mathrm{kg}$ of feed the retinoid content of the liver increased in a dose-dependent manner, whereas the retinol content of plasma increased only slightly. Vitamin A intake considerably influenced the retinyl ester concentration of the plasma.

Table 1

Retinoid and $\beta$-carotene concentrations of the blood in Japanese quail (RP and ROL $\mathrm{mg} / \mathrm{L}, \mathrm{BC} \mu \mathrm{g} / \mathrm{L}$ )

\begin{tabular}{|c|c|c|c|c|c|c|c|}
\hline \multicolumn{2}{|c|}{ Sampling } & \multicolumn{2}{|c|}{ Day 1} & \multicolumn{2}{|c|}{ Week 2} & \multicolumn{2}{|c|}{ Week 4} \\
\hline Group & Analyte & $\mathrm{H}$ & $\mathrm{R}$ & $\mathrm{H}$ & $\mathrm{R}$ & $\mathrm{H}$ & $\mathrm{R}$ \\
\hline \multirow{4}{*}{ I } & $\mathrm{RP}$ & $2.3 \pm 0.9$ & $1.2 \pm 0.5$ & $6.3 \pm 1.5$ & $6.1 \pm 0.7^{\mathrm{a}}$ & $41.5 \pm 22.9^{b}$ & $8.5 \pm 3.2^{\mathrm{h}}$ \\
\hline & ROL & $2.6 \pm 0.7$ & $3.0 \pm 0.3$ & $5.1 \pm 0.5$ & $3.2 \pm 0.4$ & $3.8 \pm 1.4$ & $3.8 \pm 0.8$ \\
\hline & $\mathrm{BC}$ & $60.7 \pm 2.8$ & $57.5 \pm 5.8$ & $57.3 \pm 5.3$ & $25.6 \pm 1.9^{c}$ & $53.9 \pm 3.8$ & $7.8 \pm 0.2^{\mathrm{ad}}$ \\
\hline & $\mathrm{RP}$ & $2.3 \pm 0.9$ & $1.2 \pm 0.5$ & $27.3 \pm 12.8^{b}$ & $24.7 \pm 5.4^{\mathrm{c}}$ & $60.1 \pm 20.8^{\mathrm{a}}$ & $16.9 \pm 9.9^{\mathrm{i}}$ \\
\hline \multirow[t]{3}{*}{ II } & ROL & $2.6 \pm 0.7$ & $3.0 \pm 0.3$ & $9.7 \pm 1.8^{\mathrm{c}}$ & $6.2 \pm 0.9$ & $13.1 \pm 3.2^{\mathrm{c}}$ & $4.1 \pm 1.2$ \\
\hline & $\mathrm{BC}$ & $60.7 \pm 2.8$ & $57.5 \pm 5.8$ & $52.3 \pm 4.7$ & $26.6 \pm 5.3^{b}$ & $43.8 \pm 2.2$ & $8.4 \pm 1.6^{\text {af }}$ \\
\hline & $\mathrm{RP}$ & $2.3 \pm 0.9$ & $1.2 \pm 0.5$ & $12.8 \pm 35.4^{\mathrm{a}}$ & $20.6 \pm 4.5^{\mathrm{a}}$ & $84.5 \pm 56.2^{\text {af }}$ & $60.5 \pm 12.5^{\mathrm{af}}$ \\
\hline \multirow[t]{2}{*}{ III } & ROL & $2.6 \pm 0.7$ & $3.0 \pm 0.3$ & $11.7 \pm 5.0$ & $5.6 \pm 1.9$ & $12.9 \pm 7.1$ & $6.4 \pm 2.3$ \\
\hline & $\mathrm{BC}$ & $60.7 \pm 2.8$ & $57.5 \pm 5.8$ & $55.7 \pm 3.1$ & $40.1 \pm 5.7$ & $44.5 \pm 4.7^{b}$ & $22.7 \pm 5.6^{\mathrm{bf}}$ \\
\hline
\end{tabular}

$\mathrm{H}=$ hens; $\mathrm{R}=$ roosters; Degree of significance $(t$-test); between values obtained on day 1 and in weeks 2 or 4 : $\mathrm{a}=\mathrm{P} \leq 0.001, \mathrm{~b}=\mathrm{P} \leq 0.01, \mathrm{c}=\mathrm{P} \leq 0.05$; between values obtained in week 2 and week 4: $\mathrm{d}=\mathrm{P} \leq 0.001, \mathrm{e}=\mathrm{P} \leq 0.01, \mathrm{f}=\mathrm{P} \leq 0.05$; between sexes: $\mathrm{g}=\mathrm{P} \leq 0.001, \mathrm{~h}=\mathrm{P} \leq 0.01, \mathrm{i}=$ $\mathrm{P} \leq 0.05$

After administration of various high levels of vitamin A to chickens the vitamin A levels of plasma, liver and egg were higher than in the control group, but plasma carotenoid levels decreased (Hashish et al., 1984; Abawi et al., 1985; Richter, 1995).

Developing ovarian follicles mature in rapid succession. Immature follicles reach maturity within 5-10 days, depending on the species (Gilbert, 1971). This hierarchy involves 5-6 large yellow follicles; marked from F1 to F5 or F6. F1 means matured, i.e. preovulatory, follicle. The growth of follicles is controlled by pituitary hormones (FSH and LH). In our present experiment, the in- 
vestigated retinoid (ROL and RP) and BC concentration of ovarian follicles (F1F5) was in the same range, indicating a continuous retinoid and carotene transport during the fast maturation period (Table 2). The deposition of RP was dose dependent. The efficiency of BC storage decreased. A similar competition between retinoids and $\mathrm{BC}$ was demonstrated in our previous investigations in the storage capacity of the yolk (Kerti et al., 1997) and in the blood (Pusztai and Bárdos, 1995), respectively.

Table 2

Retinoid and $\beta$-carotene concentrations of follicles $(\mu \mathrm{g} / \mathrm{g})$

\begin{tabular}{|c|c|c|c|c|c|}
\hline \multicolumn{2}{|c|}{ Sampling } & \multirow{2}{*}{ Day 1} & \multicolumn{3}{|c|}{ Week 4} \\
\hline Analyte & Follicle & & Group I & Group II & Group III \\
\hline \multirow[t]{6}{*}{$\mathrm{RP}$} & 1 & $74.6 \pm 12.0$ & $132.8 \pm 9.12$ & $652.3 \pm 89.5$ & $621.3 \pm 106.7$ \\
\hline & 2 & $138.5 \pm 67.8$ & $116.9 \pm 32.4$ & $566.3 \pm 70.2$ & $720.1 \pm 104.6$ \\
\hline & 3 & $117.9 \pm 56.3$ & $109.5 \pm 35.7$ & $607.4 \pm 112.1$ & $858.9 \pm 97.56$ \\
\hline & 4 & $143.4 \pm 31.5$ & $152.3 \pm 78.4$ & $630.2 \pm 124.6$ & $850.9 \pm 115.2$ \\
\hline & 5 & $95.8 \pm 17.4$ & $137.5 \pm 34.6$ & $510.4 \pm 98.9$ & $680.6 \pm 137.1$ \\
\hline & $\bar{x}(1-5)$ & $114.0 \pm 28.9$ & $129.8 \pm 16.9$ & $593.3 \pm 56.2^{b}$ & $746.3 \pm 105.1^{a e}$ \\
\hline \multirow[t]{6}{*}{ ROL } & 1 & $12.3 \pm 3.4$ & $23.6 \pm 7.3$ & $88.6 \pm 11.0$ & $84.2 \pm 9.6$ \\
\hline & 2 & $12.3 \pm 5.6$ & $24.1 \pm 5.9$ & $79.3 \pm 7.8$ & $80.3 \pm 13.2$ \\
\hline & 3 & $8.7 \pm 5.6$ & $22.6 \pm 7.5$ & $81.8 \pm 7.3$ & $92.7 \pm 7.9$ \\
\hline & 4 & $10.0 \pm 2.7$ & $21.8 \pm 8.3$ & $78.7 \pm 6.5$ & $94.0 \pm 6.3$ \\
\hline & 5 & $5.7 \pm 1.7$ & $17.9 \pm 6.3$ & $65.7 \pm 5.9$ & $91.6 \pm 9.9$ \\
\hline & $\bar{x}(1-5)$ & $9.8 \pm 2.7$ & $22.0 \pm 2.4^{c}$ & $78.8 \pm 8.3^{b f}$ & $88.6 \pm 5.9^{b f}$ \\
\hline \multirow[t]{6}{*}{$\mathrm{BC}$} & 1 & $0.6 \pm 0.08$ & $0.2 \pm 0.01$ & $0.3 \pm 0.02$ & $0.2 \pm 0.05$ \\
\hline & 2 & $0.6 \pm 0.07$ & $0.3 \pm 0.01$ & $0.2 \pm 0.05$ & $0.3 \pm 0.07$ \\
\hline & 3 & $0.5 \pm 0.18$ & $0.2 \pm 0.04$ & $0.2 \pm 0.09$ & $0.4 \pm 0.03$ \\
\hline & 4 & $0.5 \pm 0.05$ & $0.2 \pm 0.11$ & $0.1 \pm 0.09$ & $0.3 \pm 0.12$ \\
\hline & 5 & $0.5 \pm 0.08$ & $0.3 \pm 0.08$ & $0.2 \pm 0.12$ & $0.1 \pm 0.11$ \\
\hline & $\bar{x}(1-5)$ & $0.54 \pm 0.05$ & $0.24 \pm 0.05^{c}$ & $0.20 \pm 0.07^{c}$ & $0.26 \pm 0.11^{c}$ \\
\hline
\end{tabular}

Degree of significance ( $t$-test) between values obtained on day 1 and in week $4: \mathrm{a}=\mathrm{P} \leq 0.001, \mathrm{~b}=\mathrm{P} \leq$ $0.01, \mathrm{c}=\mathrm{P} \leq 0.05$; between groups at the end of the experiment: $\mathrm{d}=\mathrm{P} \leq 0.001, \mathrm{e}=\mathrm{P} \leq 0.01, \mathrm{f}=\mathrm{P} \leq$ 0.05

\section{Roosters}

As a result of treatment, the RP concentration of blood plasma rose drastically in all treated groups by the end of the second week, compared with values measured at the beginning of the study. The rate of elevation was fivefold, 20-fold 
and 17-fold in Groups I, II and III, respectively, and it was significant in all groups. These values continued to increase, but that rise was significant $(p<$ 0.05 ) only in Group III. The ROL concentration increased only slightly. Plasma BC was depressed in an inverse correlation to RA supplementation $(r=-0.59)$; it was already much lower by the second week and continued to be significantly different throughout the experiment (Table 1).

The storage of retinoids in the testicles has been found to be directly correlated with the dose used. RP and ROL concentrations and content increased over time in a dose-dependent manner (Groups II and III: $\mathrm{p}<0.01$ ). The BC concentration was inversely related to the dose (Group I: $p<0.05$ ) (Table 3). The depressed concentration of carotenoids after supplementation with high doses of vitamin A can be explained by saturation of the storage capacity. The binding sites can take up more retinoid compound from the high amounts of administered vitamin A than from carotenoids. As a consequence, the concentration of carotenoids will decrease. This mode of action was posited by Sklan et al. (1989) for the decreased hepatic storage of carotene. High doses of retinyl palmitate $(350 \mathrm{mg} / \mathrm{kg})$ significantly $(\mathrm{p}<0.05)$ increased the vitamin A levels of plasma and liver. The concentrations of two carotenoids ( $\beta$-carotene and canthaxanthine) decreased in the plasma and liver (Sklan et al., 1989). In addition to the decline of carotenoid concentrations at high doses of vitamin A, the vitamin E content of tissues also decreased considerably (Frigg and Broz, 1984; Vahl and van't Klooster, 1987).

The increase of dietary retinoid concentration caused subclinical hypervitaminosis in Groups I and II. This was indicated by the marked elevation of RP in the blood (Table 1). In the third group, hypervitaminosis indicated by cachexia and death occurred by the fourth week. The effects of excess vitamin A had already been studied in several experiments. Dietary supplementation with high doses of vitamin A $(30,000 \mathrm{IU} / \mathrm{kg}$ feed) in broiler chickens resulted in impaired growth and an increased mortality rate, but feed intake and utilisation did not change. The same change was detected in laying quails fed a diet supplemented with vitamin A at a rate of $811,000 \mathrm{IU} / \mathrm{kg}$ (Mehringer, 1987).

\section{Comparison between sexes}

There were no differences in the blood retinoid (RP and ROL) and BC concentrations between hens and roosters at the beginning of experiment (Table 1). Plasma retinoid, especially RP, concentrations were increased more markedly in female birds than in males. This difference was significant in Groups I and II in week 4 (Table 1). Retinoid content of the genital organs was higher in laying hens (Table 2) than in roosters (Table 3 ). The storage of retinoids in the gonads was found to be in a direct ratio to the doses applied. These findings indicate 
that layers are metabolically more sensitive to a vitamin A surplus. This seems to be similar to the phenomenon when oral contraceptive agents containing female sex hormones cause a marked elevation in plasma retinoids (Underwood, 1984).

Table 3

Vitamin $\mathrm{A}(\mathrm{ROL}$ and $\mathrm{RP})$ and $\beta$-carotene $(\mathrm{BC})$ concentrations of testicles

\begin{tabular}{|c|c|c|c|c|}
\hline Group & $\mu \mathrm{g} / \mathrm{g}$ & Day 1 & Week 2 & Week 4 \\
\hline \multirow[t]{3}{*}{ I } & $\mathrm{RP}$ & $6.0 \pm 1.8$ & $4.4 \pm 2.5$ & $8.8 \pm 4.1$ \\
\hline & ROL & $0.4 \pm 0.2$ & $0.2 \pm 0.1$ & $0.8 \pm 0.5$ \\
\hline & $\mathrm{BC}$ & $0.045 \pm 0.01$ & $0.029 \pm 0.01$ & $0.016 \pm 0.005^{\mathrm{af}}$ \\
\hline \multirow[t]{3}{*}{ II } & RP & $6.0 \pm 1.8$ & $14.7 \pm 6.4^{\mathrm{b}}$ & $19.3 \pm 5.2^{\mathrm{b}}$ \\
\hline & ROL & $0.4 \pm 0.2$ & $2.8 \pm 1.8^{\mathrm{b}}$ & $5.3 \pm 1.1^{\mathrm{b}}$ \\
\hline & $\mathrm{BC}$ & $0.045 \pm 0.01$ & $0.033 \pm 0.007$ & $0.020 \pm 0.005^{\mathrm{b}}$ \\
\hline \multirow[t]{3}{*}{ III } & RP & $6.0 \pm 1.8$ & $35.3 \pm 11.8$ & $178.3 \pm 65.1$ \\
\hline & ROL & $0.4 \pm 0.2$ & $3.8 \pm 1.6^{\mathrm{b}}$ & $10.6 \pm 3.6^{\mathrm{bf}}$ \\
\hline & $\mathrm{BC}$ & $0.045 \pm 0.01$ & $0.036 \pm 0.01$ & $0.028 \pm 0.009^{\mathrm{b}}$ \\
\hline
\end{tabular}

Degree of significance ( $t$-test): between values obtained on day 1 and weeks 2 or 4 : $\mathrm{a}=\mathrm{P} \leq 0.001$, $\mathrm{b}=\mathrm{P} \leq 0.01, \mathrm{c}=\mathrm{P} \leq 0.05$; between values obtained in weeks 2 and 4 : $\mathrm{d}=\mathrm{P} \leq 0.001, \mathrm{e}=\mathrm{P} \leq 0.01$, $\mathrm{f}=\mathrm{P} \leq 0.05$

The results indicate that retinoids and carotenoids (in our investigations especially ROL, RP and BC) have dissimilar storage characteristics in the genital organs of Japanese quail. This phenomenon may be attributed to the different endocrine status of layers and roosters. These metabolic characteristics prepare layers for the deposition of retinoids into follicles. Our results were obtained after an elevated dietary vitamin A supplementation. Fortification of the egg yolk with retinoids in order to produce eggs of better quality (Bárdos et al., 1996) and/or hatchability (Kerti et al., 1997) requires caution because an overdose involves the risk of hypervitaminosis in layers.

\section{Acknowledgement}

This work was supported by grants from the PhD programme of the Gödöllö University of Agricultural Sciences to A. K., and from the Higher Education Research and Development Program (FKFP) No. 0473 to L. B. 


\section{References}

Abawi, G., Sullivan, T. W. and Scheideler, S. E. (1985): Interaction of dietary fat with levels of vitamins A and E in broiler chicks. Poultry Sci. 64, 1192-1198.

Bárdos, L., Sótér, Gy. and Karchesz, K. (1996): Effect of retinyl-acetate, ascorbic acid and tocopherol supplementation of the feed on egg vitamin A content in Japanese quail. Acta Vet. Hung. 44, 213-219.

Bermudez, A. J., Swayne, D. E., Squires, M. V. and Radin, M. J. (1993): Effects of vitamin A deficiency on the reproductive system of mature White Leghorn hens. Avian Dis. 37, 247-283.

Biesalski, H., Greiff, H., Brodda, K., Hafner, G. and Bassler, K. H. (1986): Rapid determination of vitamin A (retinol) and vitamin E (alpha-tocopherol) in human serum by isocratic adsorption HPLC. Int. J. Vit. Nutr. Res. 56, 319-327.

Frigg, M. and Broz, J. (1984): Relationships between vitamin A and vitamin E in the chick. Int. J. Vit. Nutr. Res. 54, 125-133.

Gellert, R. J. (1977): Inhibition of cyclic ovarian activity in rats treated chronically with vitamin A. J. Reprod. Fert. 50, 223-229.

Gilbert, A. B. (1971): The ovary. In: Bell, D. J. and Freeman, B. M. (eds) Physiology and Biochemistry of the Fowl. Academic Press, Inc. New York, pp. 1163-1208.

Hashish, S., El-Husseiny, O. and Eissa, A. I. (1984): Effect of dietary vitamin A levels on egg production, incidence of blood spots and the intensity of egg yolk color. Poultry Sci. 63, 111-117.

Kerti, A., Bárdos, L. and Sinkovicsné Hlubik, I. (1997): Effect of retinyl acetate as feed supplementation carried out before hatching egg production on the hatchability of Japanese quail eggs (in Hungarian, with English abstract). Magyar Állatorvosok Lapja 119, 234-238.

Mehringer, U. (1987): Hypervitaminosis A in Poultry. Thesis, Ludwig-Maximilians-Universität, Munich, $218 \mathrm{pp}$.

Naber, E. C. and Squires, M. W. (1993): Vitamin profiles of eggs as indicators of nutritional status in the laying hen: Diet to egg transfer and commercial flock survey. Poultry Sci. 72, 1046-1053.

Pusztai, A. and Bárdos, L. (1995): Effects of dietary $\beta$-carotene and retinyl acetate on blood retinoid and $\beta$-carotene concentration and on in vivo ovarian steroid secretion in Japanese quail (in Hungarian, with English abstract). Magyar Állatorvosok Lapja 50, 353-355.

Richter, G. (1995): Inkorporation und Mobilisierung von Vitamin A bei Legehennen. Arch. Anim. Nutr. 48, 337-345.

Sklan, D., Yosefov, T. and Friedman, A. (1989): The effects of vitamin A, $\beta$-carotene and canthaxanthine on vitamin A metabolism and immune responses in the chick. Int. J. Vit. Nutr. Res. 59, 245-250.

Thompson, J. N., Howell, J., Pitt, G. A. and McLaughlin, C. I. (1969): The biological activity of retinoic acid in the domestic fowl and the effects of vitamin A deficiency on the chick embryo. Br. J. Nutr. 23, 471-490.

Underwood, B. A (1984): Vitamin A in animal and human nutrition. In: Sporn, M. B., Roberts, A. B. and Goodman, D. S. (eds) The Retinoids. Academic Press, New York, pp. 282-391.

Vahl, H. A. and van't Klooster, A. Th. (1987): Effects of excessive vitamin A levels in broiler rations. J. Anim. Physiol. Anim. Nutr. 57, 204-218.

Weiser, H., Probst, H. P. and Bachmann, H. (1992): Vitamin E prevents side effects of high doses of vitamin A in chicks beyond deficiency. Ann. New York Acad. Sci., 669, 396-398. 